\title{
A new method for controlling the ignition state of a regenerative combustor using a heat storage device
}

\author{
Pablo Marín, Fernando V. Díez, Salvador Ordóñez* \\ Department of Chemical and Environmental Engineering, University of Oviedo, Facultad de Química, \\ Julián Clavería 8, Oviedo 33006, SPAIN \\ * Phone: 34-985 103 437, FAX: 34-985 103 434, e-mail: sordonez@uniovi.es
}

\begin{abstract}
Regenerative oxidizers are very useful for combustion of methane-air lean mixtures $(<1 \%$ vol. and as low as $0.15 \%)$, as those generated in coal mines (ventilation air methane, VAM). However, the performance of the oxidizer is unstable, leading to overheating or extinction, when methane concentration varies. We propose a new procedure for overcoming this problem, using the heat storage concept. Thus, this issue is addressed by proposing the use of an external sensible heat storage system, added to the regenerative oxidizer, capable of storing the excess of heat released in the oxidizer during rich concentration periods, and using it to heat the feed as needed during lean concentration periods. The performance of the heat storage system has been studied by simulating the behavior of a regenerative thermal oxidizer designed to operate at $0.25 \%$ vol. nominal feed methane concentration. It was found that the regenerative oxidizer, provided with the heat storage system together with a feedback controller that regulates the heat extracted/introduced in the oxidizers can operate satisfactory, dealing with the variations in methane concentration found in ventilations of coal mines.
\end{abstract}

Keywords: ventilation air methane, methane complete combustion, unsteady state reactor, reverse flow reactor, sensible heat storage, feedback reactor control. 


\section{Introduction}

The environmental concern about methane emissions has risen in the last years, because this gas is the second contributor to global warming, after carbon dioxide. The most important sources of methane emissions are coal mines, natural gas extraction and processing facilities, landfills, etc. Among the different technologies for controlling methane in air emissions, oxidation to carbon dioxide is the most effective: methane global warming potential is 20 times higher than that of carbon dioxide, so there is a clear environmental advantage in oxidizing methane to carbon dioxide before releasing it to the atmosphere [1-3].

The most appropriate combustion technology depends on the concentration of methane in the emission. Gas turbines allow direct production of electricity from the combustion reaction, but require a high concentration of methane [4]. For lower concentrations, autothermal oxidation of methane (e.g. without the need of additional fuel) is feasible, but it requires heat exchange between the inlet and outlet streams. This heat exchange can be done using recuperative or regenerative devices $[5,6]$. Recuperative heat exchange is based on indirect heat exchangers, whereas in regenerative heat exchange, the heat of the outlet stream is first stored in a solid bed, which is later used to pre-heat the inlet stream. Due to the direct gas-to-solid heat transfer, the thermal efficiency of regenerative heat transfer is higher. For this reason, regenerative oxidizers are usually the most appropriate devices to carry out methane combustion at low concentration [7-9].

Regenerative oxidizers operate under forced unsteady-state conditions, created by periodically reversing the feed flow direction. Therefore, the heat released by the exothermic reaction is trapped inside the reactor bed between two consecutive flow reversals, being used to preheat the cold feed up to the reaction temperature. Further explanations about this technology and its applications have been exhaustively reported in recent reviews and articles cited therein [9-11].

There are two types of regenerative oxidizers, depending on the type of methane oxidation reaction: regenerative thermal oxidizers (RTO) and regenerative catalytic oxidizers (RCO). In RTO methane oxidation takes place in the gas phase at high temperature, whereas in RCO methane is oxidized on the surface of a solid catalyst. The use of a catalyst produces a marked reduction of the methane ignition temperature, and hence of the reactor operating temperature. As a consequence, the size of the reactor and the need of insulation are lower. Another important advantage of RCO is the lower temperature dependence of the combustion reaction, which results in a better reactor operation, e.g. the reactor extinction and overheating are easier to control [12-14]. RCO has also disadvantages, 
the most important ones being the high cost and deactivation of the catalyst [15]. The latter takes place, depending on the catalyst, at high temperature and in the presence of other compounds, such as water or sulfur compounds [16].

Regenerative oxidizers have succeeded at a commercial scale in the treatment of volatile organic compounds (VOC) emissions to match environmental regulations [17-19].

In industrial applications, regenerative oxidizers have to deal with changes in feed concentration upon time, as in many emissions methane concentration changes during short periods of time, even though the day-averaged concentration is relatively constant. In these situations, the reactor must be designed not only considering the nominal or time-averaged concentration, but also the rich and low concentration periods. Thus, during the rich concentration periods the reactor should be able to drain the excess of heat released by the reaction; otherwise, there is a risk of overheating, damaging the catalyst (for RCO), insulation or reactor structure (RTO) or promoting the formation of nitrogen oxides (RTO). On the contrary, during the low concentration periods, the reactor must avoid extinction conditions.

Different control strategies have been proposed in the literature to deal with these problems, as summarized as follows. Some control strategies are based on adjusting the switching time according to the feed concentration [14, 20-21]. It was experimentally demonstrated that this control can deal with moderate changes in concentration; however, for the case of sharp and sustained decreases in concentration, the reactor extinction cannot be prevented [14]. Other controllers regulate the excess of heat in the reactor by withdrawing part of the hot gas from the inside of the reactor [17, 22-26]. Another possibility is the air dilution of the feed, and the use of electrical resistances or addition of supplementary fuels for feed fuel concentrations too high or low, respectively, but in this way the system losses its autothermicity [27-28]. So, the lack of a control system able of operating autothermically at both rich and lean concentrations is widely accepted.

In the present work, we propose an alternative approach for increasing the thermal stability of regenerative oxidizers. This approach consists of using an additional heat storage system (packed bed) connected to the reactor. The mission of the heat storage system is to store the excess of heat produced in the reactor during the feed rich concentration periods, and return this heat as needed during the low concentration periods. While other control systems are designed only to deal with a type of concentration disturbance (e.g. a decrease or increase in methane concentration), the proposed control system is able to deal with both of them. Moreover, this control system maintains the reactor stable operation during lean concentration periods by using the heat stored in the proposed heat storage system, instead of using a supplementary fuel, so it is more energy efficient. 
The development of novel and more efficient heat storage systems is an active research field, particularly attractive for solar power plants [29-30]. Heat storage systems are classified into three main groups according to the way the heat is stored: sensible, latent and chemical. Latent and chemical heat storage systems are the most volume-efficient, as high amounts of heat can be stored in small volumes. However, these systems are based on the coupling with a phase change (latent) or a reaction (chemical), which limits their application to a certain, and sometimes narrow, range of operating temperature. On the contrary, sensible heat storage systems are very versatile with respect to the temperature range, the moment and the direction of the heat exchange [31]. This is particularly important for regenerative oxidizers, where the source temperature may change upon time, and the charging and discharging cycles of the heat storage system may be of different duration. In addition, they are very simple and have low cost. For this reason, a sensible heat storage system, formed by beds of refractory ceramics, is the option selected in this work.

The performance of the heat storage system has been studied for the combustion of methane in a regenerative thermal oxidizer, as RTO are more sensible to variations in the feed concentration.

The article is organized as follows. Firstly, the design of the regenerative thermal oxidizer and the corresponding heat storage system for a given feed, in this case the ventilation emission from a coal mine, is presented. Second, the heat storage system is simulated to evaluate its performance. Then, a feedback control system is proposed to regulate the action of the heat storage system connected to a RTO, in order to maintain stable reactor operation. Finally, the behaviour of the whole system, including RTO, heat storage, and controller, is analysed for the treatment a real coal mine emission.

\section{Methodology}

\subsection{Mathematical model}

Figure 1 shows a diagram of the RTO. The basic layout consists of two regenerative beds of solid material (labelled as A and B) and an open combustion chamber in between (at the top of the figure). The periodical switching of the flow direction is produced using two three-way valves located at the entrance and exit of these beds. Methane combustion takes place mainly in the combustion chamber, whereas the regenerative beds are responsible for heating the feed gas up to the reaction temperature and cooling the combustion gases and storing the heat between cycles. The mathematical model used in this work is able to simulate the dynamics of the regenerative beds and combustion chamber, predicting the evolution with time of methane concentration and 
temperature. The reactor topology depicted in Figure 1 can be reduced to a one-dimensional geometry that considers gradients only in the direction of the flow (spatial coordinate z), as indicated by the arrows.

The regenerative beds are formed by honeycomb monoliths, formed by parallel channels that allow gas flow in only one direction. The beds are also considered to operate at adiabatic conditions, which is a good approximation for insulated devices with large cross-section area. In this case, temperature gradients only exist in the direction of the flow and a one-dimensional model is enough to describe the reactor behaviour. The model has been formulated applying the mass and energy conservation equations separately to the gas and solid phases, as shown in Table 1. This type of heterogeneous model predicts the dynamics of heat exchange between the gas and solid phases accurately, which is of key importance in regenerative beds [32].

The combustion chamber is a void section with a more complex flow pattern that depends of geometry of the chamber. This section is also modelled as one-dimensional with a spatial coordinate corresponding to that of the average flow. This simplification is assumed, because the combustion chamber has a lower thermal inertia when compared to the regenerative beds, and hence do not contribute to the heat storage. The kinetics of methane combustion is considered first order on methane concentration and zero-th order on oxygen concentration, with $1.68 \cdot 10^{11} \mathrm{~s}^{-1}$ preexponential factor and $218 \mathrm{~kJ} / \mathrm{mol}$ activation energy [33]. This expression was obtained experimentally for methane-air flowing through narrow tubes with a relatively low degree of mixing (e.g. close to laminar conditions). However, in industrial reactors turbulence is promoted in the combustion chamber, resulting in mixing of methane feed with the intermediate radicals originated in the oxidation reaction. This fact enhances methane oxidation rate due to an auto-catalytic effect, resulting in a higher reaction rate. Thus, it is likely that the model of the combustion chamber underestimates the rate of reaction, resulting in conservative designs for industrial-scale RTO (actual methane conversions would be higher than the calculated).

The other physical and transport properties appearing in the equations are calculated using correlations from the literature; for further details refer to previous works in this field [32, 34-35]. Danckwerts boundary conditions are used to complete the model equations.

The mathematical model is solved using the method of lines: first, the spatial coordinate (z) is divided in a given set of intervals (200 in this case); then, the spatial derivatives of the partial differential equations are approximated by Taylor expansions; and finally, the resulting set of ordinary differential equations is solved using the MATLAB function ode15s, especially suited for stiff problems. All the calculations have been coded in a program written in MATLAB. 
The model has been validated using experiments carried out in regenerative oxidizers operated at adiabatic conditions. The description of the experimental procedure and validation has been published in previous works; different types of solid bed materials have been tested: random particles [35], honeycomb monoliths [32] and ceramic foams [34].

\section{Results and discussion}

\subsection{Design and simulation of a regenerative thermal oxidizer}

In order to perform the further studies, a RTO was designed for operating at constant (not timedepending) methane concentrations $(0.25 \%$ vol.). For lower concentrations, the reactor can extinguish, while for higher concentrations, reactor temperature will increase.

A key point in the design of a RTO is the selection of the regenerative beds material and shape. Refractory ceramics are commonly used, as they are able to operate at high temperature (up to $1200^{\circ} \mathrm{C}$ ) and present high thermal shock resistance. The latter is very important in RTO to avoid fractures in the material produced by the periodic changes in temperature created by the temperature wave shifts. According to the shape, the beds are classified into random and structured packing. Good regenerative beds have high heat capacity and surface area per unit of volume, while pressure drop is to be maintained as low as possible. In this context, monolithic structured beds offer the best balance between these properties, and for this reason they are selected in the present work $[13,36]$. The physical and geometrical properties of the selected bed are summarized in Table 2 .

Two additional specifications are fixed for the design of the RTO, gas superficial velocity in the reactor, $1 \mathrm{~m} / \mathrm{s}$ measured at normal conditions, and switching time, $120 \mathrm{~s}$. Both parameters affect the length of the regenerative beds required to achieve stable operation. As the gas surface velocity increases, larger bed length and the smaller bed diameter are required for a given feed, but pressure drop increases. Previous literature works suggest that optimum gas superficial velocity is around 1 $\mathrm{m} / \mathrm{s}$ [37]. The influence of the switching time on the required bed length to obtain stable operation is similar to that of the gas surface velocity. High switching times result in longer beds, necessary to prevent excessive heat losses leading to reactor extinction. On the other hand, low switching times present also disadvantages. On every switch of the gas flow direction, the gas contained in one bed and between the switching valves and the reactor never enters the reactor, and the methane contained in it is emitted to the atmosphere (wash-out effects). The fraction of methane emitted in 
this way is usually negligible, except for very low switching times. In addition, very low switching times reduce considerably the life of the switching valves. The selected switching time value, $120 \mathrm{~s}$, is a good balance between these two situations $[32,34]$. The model, being one-dimensional, does not require feed flow rate as design parameter. The reactor diameter is calculated for any feed flow rate, as superficial velocity has been specified.

The bed length has been calculated using the mathematical model introduced in the methodology section. The method consists in solving the model for the aforementioned conditions and increasing bed lengths, until long-term stable operation was attained. In this case, the resulting length for each regenerative bed was $1 \mathrm{~m}$. The open chamber situated in the middle of the reactor between the regenerative beds must provide residence time long enough for the methane oxidation reaction to take place. For the reactor operating conditions, e.g. gas velocity and temperature, and based on the kinetics of the reaction, the length required is $1.5 \mathrm{~m}$.

Figure 2 shows the gas temperature and methane concentration profiles at the beginning, the middle and the end of a cycle at pseudo-steady state for the designed RTO. In the regenerative beds, temperature increases or decreases almost linearly, the temperature profile moving forward or backwards, depending on the gas flow direction. In the middle of the reactor, where the open chamber is situated and most methane reacts, the temperature profile presents a plateau of 950 으 maximum temperature. This simulation indicates that the designed regenerative beds are able to heat the feed up to the reaction temperature using the heat stored in the beds, producing almost total methane conversion, and preventing the extinction of the reactor.

\subsection{Design of the heat storage system}

In this work we propose the addition of a heat storage system to the RTO. Its purpose is to exchange heat with the RTO, extracting heat from it during the high feed methane concentration periods and introducing heat into the reactor during low feed concentration periods. In order to achieve fast response and avoid asymmetries in the reactor temperature profiles, the heat storage system is connected to the reactor in the middle point of the empty reaction chamber, as shown in Figure 1. The heat storage system must be able of exchanging heat at $900-950^{\circ} \mathrm{C}$, the gas temperature in this point. The additional heat storage system proposed in this work is a packed bed similar to the two regenerative beds of the conventional RTO: it consists of a honeycomb monolithic bed with the same size and properties as each of the regenerative beds of the RTO (Table 2). This selection is done 
looking for homogeneity with the other beds, although the heat storage system could be larger or smaller, depending on the desired thermal capacity.

The RTO equipped with the heat storage system is depicted in Figure 1. The bed situated on the right side (labelled C) is the one corresponding to the heat storage system, while the other two (labelled A and B) are part of the conventional RTO. The diagrams represent the heat storage system in two situations: charging, or accumulating heat (Figure 1a), and discharging or releasing heat (Figure 1b). Notice that the RTO is represented in both diagrams with gas flowing from the left bed to the middle bed, but this flow is periodically reversed. The following explains the actuation of the heat storage system for changes in the feed concentration.

When the feed concentration increases above the nominal value $(0.25 \%$ methane), excess heat is released by the combustion in the open chamber, and gas and bed temperature increase. In order to avoid overheating of the reactor, part of the hot gas is diverted from the reactor chamber to the heat storage bed $\mathrm{C}$, instead of flowing through the second RTO regenerative bed $\mathrm{B}$. Thus, the excess energy is stored in this bed at the reaction temperature (900-950ㅇ) (Figure 1a), and the cooled gas is sent to the stack. On the contrary, when the feed concentration decreases below the nominal value, the heat released by the reaction is not enough to maintain autothermal operation, and, in absence of the heat storage system, the reactor temperature would start to decrease. This would result eventually in reactor extinction, the time required for this to happen depending on the magnitude and extension of the concentration decrease. This issue can be overcome by using the heat stored previously in the heat storage bed C. This is accomplished by splitting the feed gas between beds $A$ and $C$ by means of a three-way valve. Both gas streams merge in the reaction chamber, were combustion occurs, and then exit the system through bed B. The fraction of gas that circulates through the heat storage bed $\mathrm{C}$ can be regulated by the position of the valves. This system results in higher average temperature of the gas when it enters the combustion chamber (as it extracts heat from beds $A$ and $C$ ), enough to produce methane combustion, and the whole system is able of operating autothermically for an extended period of time.

The heat storage system can also be used to deal with flow rate disturbances. In this case, an increase on the flow rate would cause the regenerative beds $A$ or $B$ to be too short to heat up the feed up to the reaction temperature. This can be overcome by bypassing part of the feed through the heat storage bed $\mathrm{C}$, as explained before for the case of a low concentration disturbance. In a similar way, the overheating produced at flow rates lower than the nominal is solved by extracting the excess of heat from the combustion chamber. For simplicity, only concentration disturbances are considered in the present work. 


\subsection{Simulation of the heat storage system}

The RTO including the heat storage system has been simulated using the mathematical model described in the methodology section, completed with the required equations, and the boundary conditions in the combustion chamber modified in order to account for the additional bed. In this context, a new variable has been defined: the fraction of gas extracted $\left(f_{\text {extr }}\right)$, defined as the ratio of the gas flow rate extracted (fed to the heat storage bed $\mathrm{C}$ ) to the total feed gas flow rate. $\mathrm{f}_{\text {extr }}$ plays a key role in the performance of the heat storage system, and its sign indicates the direction of heat extraction: If $f_{\text {extr }}$ is positive, the gas is extracted from the combustion chamber to the heat storage system (bed charging); when negative, the gas is extracted from the heat storage to the combustion chamber (bed discharging).

To assess the influence of the fraction of gas extracted on the RTO behaviour, a simulation study was conducted as follows. Initially, the reactor was simulated until reaching pseudo-steady state for the nominal feed concentration $\left(0.25 \%\right.$ vol. methane) and with no gas extraction $\left(f_{\text {extr }}=0\right)$. Then, two disturbances in methane feed concentration were introduced: a step change from 0.25 to $0.45 \%$ and a step change from 0.25 to $0.15 \%$. In the first case the heat storage bed is considered to be initially cold (at $25^{\circ} \mathrm{C}$ ), whereas in the second case the heat storage bed is considered to be preheated to $950^{\circ} \mathrm{C}$. Moreover, different values of the fraction of gas extracted were considered in each case. Results are summarized in Figure 3, where the evolution with time of the temperature of the combustion chamber is depicted (the corresponding step increase or decrease in concentration takes place at time zero).

When methane feed concentration increases and no heat storage system is used $\left(f_{\text {extr }}=0\right)$, temperature in the combustion chamber increases up to $1100^{\circ} \mathrm{C}$, as shown in Figure $3 \mathrm{a}$. When using increasing fractions of gas extracted (from $8 \%$ to $12 \%$ ) the amount of heat stored in the RTO between cycles decreases, and hence the temperature of the combustion chamber also decreases. New stable pseudo-steady states are achieved for $f_{\text {extr }} 8 \%$ and $10 \%$, with average chamber temperatures 1000 and $900{ }^{\circ} \mathrm{C}$, respectively, while for $\mathrm{f}_{\text {extr }}$ higher than $12 \%$, the reactor extinguishes (too much heat has been withdrawn). The step change in methane concentration from 0.25 to $0.15 \%$ produces the fast extinction of the reactor if no heat storage system is used. Conversely, the use of the heat storage bed that introduces additional heat in the reactor can delay greatly the extinction. This depends on the fraction of gas by-passed through the heat storage bed, as shown in Figure $3 b$. For $f_{\text {extr }}=-2 \%$, the reactor extinguishes, whereas for $f_{\text {extr }}=-4 \%$ and $-6 \%$, the reactor achieves a pseudo-steady state with average temperatures in the combustion chamber 875 and $925^{\circ} \mathrm{C}$, respectively. 
After examining the results of the simulations with different fraction of gas extracted, it was concluded that the optimum is the one that produces a temperature in the combustion chamber similar to the nominal (e.g. at the nominal concentration of $0.25 \%$, see Figure 2 ). These conditions results in a high methane conversion (>99\%) and avoids overheating. Figure 4 compares in terms of temperature and concentration profiles the performance of the reactor at nominal conditions $(0.25 \%$ methane and $f_{\text {extr }}=0$ ) and the two disturbance scenarios considered, each one operated at their corresponding optimum $\mathrm{f}_{\text {extr }}: 10 \%$ and $-6 \%$, respectively for the high and low concentration disturbances. Temperature in the combustion chamber is the same in all cases, which means that the amount of heat extracted has been optimized according to our criterion. It should be noted that for the $0.45 \%$ methane disturbance, temperature in the regenerative beds ( $A$ and $B$ ) is lower than the nominal, whereas for the $0.15 \%$ methane disturbance is higher. This is a consequence of heat extraction and addition, respectively [38]. The concentration profile shown in Figure 4 demonstrates that the use of the heat storage do not affect methane conversion ( $>99 \%$ in all cases), provided that the chamber temperature is high enough. This was implicit in our criterion for the optimization of the heat storage system.

Finally, the behaviour of the heat storage system is analysed separately in terms of the evolution of the bed $\mathrm{C}$ temperature profiles, when the system is operated at the optimum $\mathrm{f}_{\text {extr. }}$. Figure $5 \mathrm{a}$ for the $0.45 \%$ methane disturbance shows the typical profile of a charging bed, with a temperature front moving from the bed entrance to the exit. Bed temperature is initially low, and increases gradually until the front reaches the bed end. At this point, the heat storage capacity of the bed has been completed and no more heat can be trapped by the heat storage system. The temperature of the gas emitted will then increase gradually, although the diversion of part of the reacted gas to the stack through bed $\mathrm{C}$ will continue preventing the reactor overheating. In Figure $5 \mathrm{~b}$, corresponding to the $0.15 \%$ methane disturbance, as part of the cold feed is introduced in the heat storage bed C, initially pre-heated at $950^{\circ} \mathrm{C}$, a cold front is developed that moves gradually from right to left. The capacity of the heat storage bed is finite, so if the feed low concentration disturbance lasts enough as to allow the cold front to reach the end of the bed, the heat storage bed $C$ would lose its capacity to pre-heat the feed, methane conversion would decrease, and the reactor would finally extinguish. The time required for this to happen depends on the bed length and properties (in the present case more than $2 \mathrm{~h}$ ). The designer can tailor the heat storage system to deal with the magnitude and length of concentration disturbances that takes place in a specific application. 


\subsection{Design of a control system}

The RTO equipped with the heat storage bed requires a control system, either manual or automatic, able of identifying if the heat storage bed must be charging or discharging, and regulating the gas flow rate required for proper operation, in order to avoid both reactor extinction or overheating.

PID (proportional-integral-derivative) feedback controllers are the most common in industrial applications, as they are simple, cheap and easy to integrate in a wide range of RTO, and is the controller selected in this work. The controller algorithm determines how to change one manipulated variable $(m)$ for a given error or difference $(e)$ between the desired (set-point) and actual value of the controlled variable. The controller algorithm can contain three types of actions: proportional to the error $(\mathrm{P})$, proportional to the integral of the error $(\mathrm{I})$, and proportional to the derivative of the error (D). The standard form of the PID controller is the following:

$m=m_{s}+K_{C}\left(e+\frac{1}{\tau_{I}} \int e d t+\tau_{D} \frac{d e}{d t}\right)$

Where $K_{C}, \tau_{I}$, and $\tau_{D}$ are the controller parameters, determined during the tuning procedure, and $m_{s}$ is the nominal (pseudo-steady state) value of the manipulated variable.

The selection of the appropriate controlled variable is very important. It must reflect the state of the reactor (e.g. if the reactor is close to extinction or running in overheating) be easily measurable, and have a fast dynamic response to both the most common disturbances (e.g. methane feed concentration) and to changes in the manipulated variable, in this case the fraction of gas extracted $\left(f_{\text {extr }}\right)$. The gas temperature in the middle of the combustion chamber $\left(T_{\text {cha }}\right)$, situated between the two regenerative beds, satisfies these requirements. This temperature provides a direct idea of the reactor state, because a low value means low reaction rate and possible reactor extinction, whereas a high value indicates overheating. At nominal conditions, the pseudo-steady state value of the controlling variable is $900^{\circ} \mathrm{C}$ (Figure 2). This value is chosen as set-point (SP) for the controller.

The feedback controller will act as follows: gas temperature in the middle of the open chamber is measured continuously and compared to the set-point value, the difference or error is introduced in the controller algorithm, eq. (1), which gives a value for the fraction of gas extracted from or to the reactor. In real apparatuses, the valves system would be manipulated in order to get this value. For a positive error ( $\mathrm{SP}>\mathrm{T}_{\mathrm{cha}}$ ), the controller directs a fraction of the gas feed to the heat storage bed and then to the reactor chamber (the heat storage bed discharges, $m$ and $f_{\text {extr }}<0$ ), whereas for a negative error the controller acts in the opposite way (part of the gas is directed from the 
combustion chamber to the heat storage bed, which charges). Notice that the controller gain must be negative $\left(K_{C}<0\right)$ to achieve the desired response; the controller is direct acting.

The controller algorithm has been introduced into the reactor model described in the methodology section, in order to simulate the behaviour of the complete system, formed by the regenerative thermal oxidizer reactor, heat storage system, and controller. Simulations require the controller to be tuned, e.g. appropriate values for the controller parameters, $K_{C}, \tau_{I}$, and $\tau_{D}$, must be specified. The controller tuning has been done using the ITAE criterion, based on the minimization of the integral of the time weighted absolute error. This criterion offers a good balance between controller response speed and stability. To apply this tuning method, the dynamics of the chamber temperature has been approximated by a first order system with dead time. The following equations correspond to the time and Laplace forms of this system:

$$
\begin{gathered}
T(t)=\bar{T}+A K_{p}\left(1-e^{-(t-\theta) / \tau}\right) \\
G(s)=\frac{T(s)}{m(s)}=\frac{K_{p} e^{-\theta s}}{\tau s+1}
\end{gathered}
$$

The parameters of the system, $K_{p}, \tau$ and $\theta$, have been determined using the step response method applied to the RTO-heat storage model. This method is summarized as follows. First, the reactor is simulated up to the steady-state at nominal conditions (the design conditions in Table 2) with no gas extraction, then a step change, $A$, of $\pm 1 \%$ is introduced in the manipulated variable -the sign of the step depends on the direction of the gas extraction, to (+) or from (-) the heat storage bed-, and the evolution with time of the combustion chamber temperature is recorded until a new pseudo-steady state is achieved. At this point, one should consider that the chamber temperature depends not only as a function of the feed concentration, but also due to the periodic switch of the flow direction, inherent to RTO operation. The later introduces high frequency periodicity in the signal that must be filtered before any analysis of the response curve. The use of a moving-average filter eliminates this noise of the combustion chamber temperature signal, and produces a smooth response curve.

The system parameters, determined directly from the temperature response curve for gas being extracted to and from the heat storage bed are given in Table 3. Notice that the dead time $(\theta)$ is 240 $s$ in both cases, which is twice the switching time of RTO. This is in agreement with the behaviour observed for the RTO in the previous section, where it was observed that the reactor was affected by a disturbance one cycle after having taken place. The time constant $(\tau)$ is found to be a rather high 
value of around $2 \mathrm{~h}$, meaning that the evolution to another pseudo-steady state requires long time. This is a consequence of the high thermal inertia of the RTO regenerative beds ( $A$ and $B$ ).

For simplicity, the controlled reactor model does not account for the dynamics of the other elements of the control loop, apart of the reactor, such as the control valve or the thermocouples. Considering the high time constant $(2 \mathrm{~h}$ ) and dead time ( $240 \mathrm{~s}$ ) of the reactor, the delay produced by these other elements can be neglected in the calculation of the stability of the reactor and the tuning of the controller.

The expressions used for tuning the controller, based on the ITAE criterion for a first order system with dead time and a disturbance input [39] are summarized in Table 4. Two controllers have been tuned, $\mathrm{P}$ and $\mathrm{Pl}$; the PID is not recommended for RTO, because the flow switch produces a periodic change in the chamber temperature, and hence in the error, that when processed by the derivative action of the controller, results in too broad changes in the manipulated variable. The controller is expected to control the reactor in the medium to long period, but not in the short period of a reactor cycle. Depending on the heat storage regime, e.g. gas being extracted to or from the heat storage bed, a different transfer function was fit, and different sets of tuning parameters were calculated. As shown, the integral time $\left(\tau_{I}\right)$ is very similar but the controller gain $\left(K_{C}\right)$ differ substantially in both cases.

\subsection{Simulation of the controlled heat storage system}

In this section, the behaviour of a RTO equipped with a controlled heat storage system is simulated for two feed concentration disturbances: a step increase from 0.25 to $0.45 \%$ methane and a step decrease from 0.25 to $0.15 \%$ methane. The simulations were carried out as explained: first, the controlled RTO was simulated for the nominal feed concentration $(0.25 \%$ methane) for $40 \mathrm{~min}$ (time enough to achieve the pseudo-steady state), and then the corresponding step concentration disturbance was introduced. During all the simulation the chamber temperature set-point was 900 ․ F. Figure 6 shows the results of the simulations in terms of the manipulated $\left(f_{\text {extr }}\right)$ and controlled $\left(T_{\text {cha }}\right)$ variables for the $\mathrm{P}$ and PI controllers, for comparison purposes.

Figure 6 a and c correspond to the rich concentration disturbance, which produces an increase in the chamber temperature. The response of both $\mathrm{P}$ and $\mathrm{PI}$ controllers is an increase in $\mathrm{f}_{\text {extr }}$ to $20-30 \%$, as more heat is released in the reactor and the chamber temperature increases. The combustion chamber temperature increases first, reaching a maximum, and then decreases slowly, reaching a 
new pseudo-steady state. At this point, the excess of heat is extracted to the heat storage system and the chamber temperature oscillates between acceptable limits. With no heat storage system, chamber temperature would reach $1100^{\circ} \mathrm{C}$. The response of both controllers is rather similar, the most remarkable difference being that the PI controller results in $f_{\text {extr }}$ and chamber temperature slightly higher than the P controller.

Figure 7a depicts the gas temperature profiles at the middle of a cycle at the new pseudo-steady state (after $25 \mathrm{~min}$ ) for the $\mathrm{P}$ and $\mathrm{PI}$ controllers and compares them to the nominal conditions $(0.25 \%$ methane) with no heat storage. The plateau temperature of the controlled reactor is $970^{\circ} \mathrm{C}$, slightly higher than the nominal one, $950^{\circ} \mathrm{C}$, but the controllers are able to maintain the reactor within the operating limits.

When the lean concentration disturbance is introduced, Figure $6 b$ and $d$, the temperature in the combustion chamber decreases initially below the set-point temperature, $900^{\circ} \mathrm{C}$. The controllers respond immediately with a decrease of $\mathrm{f}_{\text {extr }}$ to negative values. This introduces heat into the reactor from the heat storage system (initially at $950^{\circ} \mathrm{C}$ ) and compensates the decrease in methane feed concentration, maintaining the stability of the reactor. In this case, the new pseudo-steady state is reached very quickly, in less than $10 \mathrm{~min}$, and both controllers perform very similarly, although the PI controller results in a slightly higher chamber temperature. The average pseudo-steady state $f_{\text {extr }}$ is $10 \%$, which results in an average $T_{\text {cha, }}$ very close to the set-point. The new pseudo-steady state temperature profiles (after $25 \mathrm{~min}$ ) at the mid cycle of Figure $7 \mathrm{~b}$ show that the plateau temperature is $910^{\circ} \mathrm{C}$ for the case of the controlled reactor, a bit lower than $950^{\circ} \mathrm{C}$ corresponding to the nominal. For this disturbance, the uncontrolled reactor would extinguish.

The simulations of the controlled RTO with heat storage system demonstrate that the proposed system improves the RTO performance considerably, as the controller is able of selecting automatically the appropriate value of the fraction of gas extracted so that the reactor is able of overcoming both rich and lean feed concentration periods.

\subsection{Simulation for a real coal mine emission}

The aim of this section is to simulate the response of the RTO equipped with a controlled heat storage system when treating real emissions. Methane concentration in real emissions may change continuously in a more or less random manner, according to the process producing the emission. For instance, in coal mine ventilations, methane concentration varies according to the workload of the 
mine and mainly to the atmospheric pressure, low atmospheric pressure causing a higher release of methane from the coal bed. On the other hand, flow rate changes very little with time in many emissions, as it is controlled by the ventilation system. In this section, a real emission from ventilation air of a coal mine is used as test case. The change in methane concentration upon time, determined experimentally for a real emission is depicted in Figure 8a (red line): concentration varies from a maximum value of $0.51 \%$ to a minimum of $0.26 \%$ over a period of $3 \mathrm{~h}$. Total gas flow rate was constant.

The simulation has been done using the RTO and heat storage system designed previously, and for the same operating conditions (except methane concentration). The heat storage system is controlled by a $\mathrm{P}$ controller with the tuning parameters in Table 4 and chamber temperature $900 \circ \mathrm{C}$ as set-point; according to the direction of the heat extraction, determined by the sign of the error and $f_{\text {extr }}$, the corresponding set of tuning parameter is used. The initial conditions correspond to the pseudo-steady state at nominal concentration ( $0.25 \%$ methane).

Simulation results are shown in Figures 8 and 9. The evolution of outlet methane concentration, depicted in Figure 8a (green line), is zero during the whole simulation period, which demonstrates that the reactor succeed in treating the emission, regardless of the changes in feed concentration. Figure $8 \mathrm{~b}$ and $\mathrm{c}$ represent the variation with time of the fraction of feed gas extracted and combustion chamber temperature, respectively. It can be observed that the combustion chamber temperature is maintained within the range $850-1050 \circ \mathrm{C}$, preventing both reactor extinction and overheating. The fraction of heat extracted, $f_{\text {extr }}$, takes values from 10 to $30 \%$ during rich concentration periods, whereas for lean concentration periods, decreases to $-10 \%$. Figure 9 depicts the temperature and concentration profiles at the mid cycle for every four cycles. These plots create a thick set of line profiles, useful to determine the boundaries during the whole period of time. Thus, it can be seen that the difference between the lower and upper bounds in the temperature profile is narrow (930-965ㅇ $\mathrm{C}$ in the plateau), which means that the control system performs well.

To sum up, according to the simulations, the reactor succeeded in dealing with the rich and lean concentration periods of a real methane emission from a coal mine ventilation air.

\section{Conclusions}

The use of an additional sensible heat storage bed, connected to a regenerative thermal oxidizer (RTO) is proposed to improve the performance of RTO for variations in feed concentration, 
preventing both reactor overheating and extinction. The purpose of the heat storage system is to trap the excess heat during rich feed periods and to return this heat back to the reactor as needed during low feed concentration periods. Simulations of such a system were carried out to identify the influence on the system of the manipulated variable, the fraction of gas extracted from the combustion chamber $\left(f_{\text {extr }}\right)$. It was concluded that for a step increase in methane feed concentration from 0.25 to $0.45 \%$, the optimum $f_{\text {extr }}$ was $10 \%$, while for a step decrease from 0.25 to $0.15 \%$, the optimum $\mathrm{f}_{\text {extr }}$ was $-6 \%$.

The performance of the heat storage system was improved by the use of a control system, which is able to determine the required $\mathrm{f}_{\text {extr }}$ at a given moment by measuring the temperature in the reactor open chamber. The controller was tuned and its performance evaluated by means of simulations. It was found that the controller was able of avoiding both overheating and extinction when step concentration changes take place.

Finally, the response of the reactor to a real methane emission from a coal mine ventilation air, with methane concentration changing continuously, was simulated. It was demonstrated that the controller performs well for this real emission, as the controller maintained the reactor temperature within safe limits by setting the adequate values for $f_{\text {extr }}$.

\section{Acknowledgements}

This work was supported by the Research Fund for Coal and Steel of the European Union (contract UE-10-RFCR-CT-2010-00004). N. Canto, A. González and E. Ongallo (HUNOSA-Spain) are acknowledged for providing us information about emission patterns in the coal shafts of the company.

\section{Nomenclature}

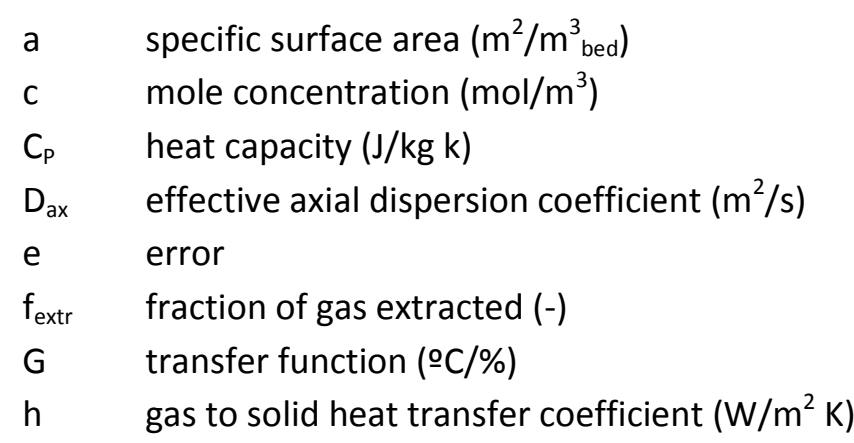




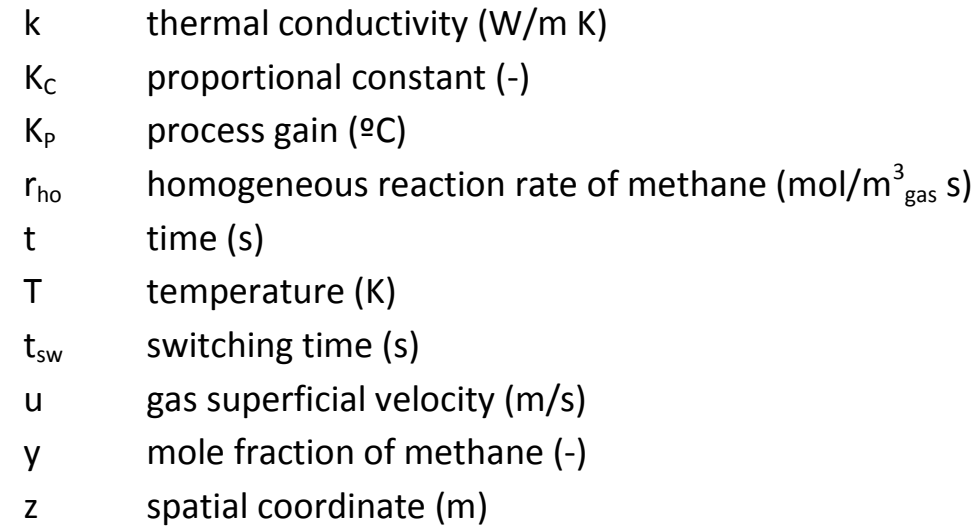

\section{Greek symbols}

$\begin{array}{ll}\Delta H & \text { reaction enthalpy }(\mathrm{J} / \mathrm{mol}) \\ \varepsilon_{\mathrm{b}} & \text { bed porosity }(-) \\ \theta & \text { dead time }(\mathrm{s}) \\ \rho & \text { density }\left(\mathrm{kg} / \mathrm{m}^{3}\right) \\ \tau & \text { process time constant }(\mathrm{s}) \\ \tau_{1} & \text { integral time }(\mathrm{s})\end{array}$

\section{Subscripts}

0 inlet

cha combustion chamber

G gas

S solid

\section{Acronyms}

PID proportional-integral-derivative

RCO regenerative catalytic oxidation

RTO regenerative thermal oxidation

VAM ventilation air methane

VOC volatile organic compound 


\section{Caption to figures}

Figure 1 Working principle of the heat storage system for the RTO. (a) HS bed charging. (b) HS bed discharging.

Figure 2 RTO design: evolution of temperature (a) and methane concentration (b) profiles during a cycle at the pseudo-steady state. Arrows indicate the gas flow direction. The arrow indicates the direction of the gas flow and hence the movement direction of the profiles, and the dashed lines the boundaries between the regenerative beds ( $A$ and $\mathrm{B})$ and the combustion chamber.

Figure 3 RTO with heat storage: influence of the fraction of gas extracted.

(a) Step change in methane concentration from 0.25 to $0.45 \% . f_{\text {extr }}=0 \%(-), 8 \%(-)$, $10 \%(-)$ and $12 \%(-)$.

(b) Step change in methane concentration from 0.25 to $0.15 \% . f_{\text {extr }}=0 \%(-),-2 \%(-)$, $-4 \%(-)$ and $-6 \%(-)$.

Figure 4 RTO with heat storage: performance of the RTO in terms of pseudo-steady state temperature (a) and methane concentration (b) profiles at mid cycle. Arrows indicate the gas flow direction. The dashed lines indicate the boundaries between the regenerative beds $(A$ and $B$ ) and the combustion chamber.

HS bed charging (-): $0.45 \%$ methane, $f_{\text {extr }}=10 \%$.

No HS bed $(-): 0.25 \%$ methane, $f_{\text {extr }}=0$.

HS bed discharging (-): $0.15 \%$ methane, $f_{\text {extr }}=-6 \%$.

Figure 5 RTO with heat storage: temperature dynamics of the heat storage bed C. Evolution of the bed temperature profiles with time (every 4 minutes), corresponding to the end of the RTO cycle.

(a) HS bed charging: $0.45 \%$ methane, $f_{\text {extr }}=10 \%$.

(b) HS bed discharging: $0.15 \%$ methane, $f_{\text {extr }}=-6 \%$.

Arrows indicate the time and gas flow directions.

Figure 6 RTO with controlled heat storage: response of P (-) and PI (-) controllers to a step change in methane feed concentration from $0.25 \%$ to $0.45 \%$ ( $a$ and $c$ ) and $0.15 \%$ (b 
and $d$ ). The step change is introduced at $t=0$. Dashed line: controller set-point temperature $(900 \circ \mathrm{C})$.

Figure 7 RTO with controlled heat storage: temperature profiles in the RTO at the middle of a cycle (25 min) for the rich (a) and lean (b) feed concentration disturbances. ( - ) nominal conditions (0.25\%), (-) P controller and (-) PI controller. Arrows indicate the gas flow direction.

Figure 8 RTO with controlled heat storage: performance for a real coal mine emission. Evolution of methane concentration (a) at the inlet $(-)$ and outlet $(-)$, fraction of gas extracted (b) and combustion chamber temperature (c). Dashed line: controller setpoint temperature.

Figure 9 RTO with controlled heat storage: performance for a real coal mine emission. Temperature (a) and methane concentration (b) profiles at the middle of a cycle obtained during $3 \mathrm{~h}$. Arrows indicate the gas flow direction. 


\section{List of tables}

Table 1. Mathematical model for the regenerative thermal oxidizer and the heat storage system.

Table 2. Operating conditions and physical properties.

Table 3.Parameters of the first order with dead time transfer function fitted to the RTO with heat storage system.

Table 4. Controller tuning based on the ITAE criteria for the RTO with heat storage system. 


\section{References}

[1] Karakurt I, Aydin G, Aydiner K. Mine ventilation air methane as a sustainable energy source. Renewable and Sustainable Energy Reviews 2011;15(2):1042-1049.

[2] Warmuzinski K. Harnessing methane emissions from coal mining. Process Safety and Environmental Protection 2008;86(5):315-320.

[3] Badr O, Probert SD, O'Callaghan PW. Atmospheric methane: Its contribution to global warming. Applied Energy 1991;40(4):273-313.

[4] Yin J, Su S, Yu XX, Weng Y. Thermodynamic characteristics of a low concentration methane catalytic combustion gas turbine. Applied Energy 2010;87(6):2102-2108.

[5] Vijayan V, Gupta AK. Combustion and heat transfer at meso-scale with thermal recuperation. Applied Energy, 2010; 87(8):2628-2639.

[6] Shirsat V, Gupta AK. A review of progress in heat recirculating meso-scale combustors. Applied Energy, 2010; 88(12):4294-4309.

[7] Abdul Mujeebu M, Abdullah MZ, Abu Bakar MZ, Mohamad AA, Abdullah MK. Applications of porous media combustion technology - A review. Applied Energy, 2009; 86(9):1365-1375.

[8] Cho ES, Danon B, Jong W, Roekaerts DJEM. Behavior of a $300 \mathrm{~kW}_{\text {th }}$ regenerative multi-burner flameless oxidation furnace. Applied Energy, 2011; 88(12):4952-4959.

[9] Su S, Beath A, Guo H, Mallett C. An assessment of mine methane mitigation and utilisation technologies. Progress in Energy and Combustion Science 2005;31(2):123-170.

[10] Matros YS, Bunimovich GA. Reverse-Flow Operation in Fixed Bed Catalytic Reactors. Catalysis Reviews 1996;38(1):1 - 68.

[11] Barresi AA, Baldi G, Fissore D. Forced unsteady-state reactors as efficient devices for integrated processes: Case histories and new perspectives. Industrial \& Engineering Chemistry Research 2007;46(25):8693-8700.

[12] Gosiewski K, Matros YS, Warmuzinski K, Jaschik M, Tanczyk M. Homogeneous vs. catalytic combustion of lean methane-air mixtures in reverse-flow reactors. Chemical Engineering Science 2008;63(20):5010-5019. 
[13] Marin P, Hevia MAG, Ordonez S, Diez FV. Combustion of methane lean mixtures in reverse flow reactors: Comparison between packed and structured catalyst beds. Catalysis Today 2005;105(3-4):701-708.

[14] Marin P, Ho W, Ordonez S, Diez FV. Demonstration of a control system for combustion of lean hydrocarbon emissions in a reverse flow reactor. Chemical Engineering Science 2010;65(1):5459.

[15] Matros YS, Bunimovich GA, Patterson SE, Meyer SF. Is it economically feasible to use heterogeneous catalysts for VOC control in regenerative oxidizers? Catalysis Today 1996;27(12):307-313.

[16] Ordóñez $S$, Hurtado $P$, Sastre $H$, Diez FV. Methane catalytic combustion over $\mathrm{Pd} / \mathrm{Al}_{2} \mathrm{O}_{3}$ in presence of sulphur dioxide: deactivation modelling. Applied Catalysis A: General 2004;259: 41-48.

[17] Bannai M, Houkabe A, Furukawa M, Kashiwagi T, Akisawa A, Yoshida T, Yamada H. Development of efficiency-enhanced cogeneration system utilizing high-temperature exhaust-gas from a regenerative thermal oxidizer for waste volatile-organic-compound gases. Applied Energy 2006;83(9):929-942.

[18] Abanto J, Reggio M, Painchaud-Ouellet S. On the design of the RTO unit using CFD. Applied Thermal Engineering 2006;26(17-18):2327-2335.

[19] Dvorak R, Stulir R, Cagas P. Efficient fully controlled up-to-date equipment for catalytic treatment of waste gases. Applied Thermal Engineering 2007;27(7):1150-1157.

[20] Barresi AA, Vanni M. Control of catalytic combustors with periodical flow reversal. Aiche Journal 2002;48(3):648-652.

[21] Budman H, Kzyonsek M, Silveston P. Control of a nonadiabatic packed bed reactor under periodic flow reversal. Canadian Journal of Chemical Engineering 1996;74(5):751-759.

[22] Li Z, Qin Z, Zhang Y, Wu Z, Wang H, Li S, Shi R, Dong M, Fan W, Wang J. A control strategy of flow reversal with hot gas withdrawal for heat recovery and its application in mitigation and utilization of ventilation air methane in a reverse flow reactor. Chemical Engineering Journal 2013;228(0):243-255.

[23] Nieken U, Kolios G, Eigenberger G. Control of the ignited steady state in autothermal fixedbed reactors for catalytic combustion. Chemical Engineering Science 1994;49(24B):5507-5518. 
[24] Balaji S, Lakshminarayanan S. Heat removal from reverse flow reactors used in methane combustion. Canadian Journal of Chemical Engineering 2005;83(4):695-704.

[25] Fuxman AM, Forbes JF, Hayes RE. Characteristics-based model predictive control of a catalytic flow reversal reactor. Canadian Journal of Chemical Engineering 2007;85(4):424-432.

[26] Gosiewski K, Warmuzinski K. Effect of the mode of heat withdrawal on the asymmetry of temperature profiles in reverse-flow reactors. Catalytic combustion of methane as a test case. Chemical Engineering Science 2007;62(10):2679-2689.

[27] Fissore D, Barresi AA. Robust control of a reverse-flow reactor. Chemical Engineering Science 2008;63(7):1901-1913.

[28] Nieken U, Kolios G, Eigenberger G. Control of the ignited steady state in autothermal fixedbed reactors for catalytic combustion. Chemical Engineering Science 1994;49(24, Part 2):5507-5518.

[29] Gil A, Medrano M, Martorell I, Lázaro A, Dolado P, Zalba B, Cabeza LF. State of the art on high temperature thermal energy storage for power generation. Part 1-Concepts, materials and modellization. Renewable and Sustainable Energy Reviews 2010;14(1):31-55.

[30] Medrano M, Gil A, Martorell I, Potau X, Cabeza LF. State of the art on high-temperature thermal energy storage for power generation. Part 2-Case studies. Renewable and Sustainable Energy Reviews 2010;14(1):56-72.

[31] Daschner R, Binder S, Mocker M. Pebble bed regenerator and storage system for high temperature use. Applied Energy (0).

[32] Marín P, Ordóñez S, Díez FV. Monoliths as suitable catalysts for reverse-flow combustors: modeling and experimental validation. AIChE Journal 2010;56(12):3162-3173.

[33] Niessen WR. Combustion and incineration processes. 3rd ed. Marcel; 2002.

[34] Thompson CR, Marín P, Díez FV, Ordóñez S. Evaluation of the use of ceramic foams as catalyst supports for reverse-flow combustors. Chemical Engineering Journal 2013;221(0):44-54.

[35] Fissore D, Barresi AA, Baldi G, Hevia MAG, Ordóñez S, Díez FV. Design and testing of smallscale unsteady-state afterburners and reactors. Aiche Journal 2005;51(6):1654-1664.

[36] Amelio M, Morrone P. Numerical evaluation of the energetic performances of structured and random packed beds in regenerative thermal oxidizers. Applied Thermal Engineering 2007;27(4):762770. 
[37] Marin P, Ordonez S, Diez FV. Simplified design methods of reverse flow catalytic combustors for the treatment of lean hydrocarbon-air mixtures. Chemical Engineering and Processing 2009;48(1):229-238.

[38] Marin P, Ordonez S, Diez FV. Procedures for heat recovery in the catalytic combustion of lean methane-air mixtures in a reverse flow reactor. Chemical Engineering Journal 2009;147(2-3):356-365.

[39] Seborg DE, Edgar TF, Mellichamp DA, III FJD. Process dynamics and control. 3rd ed. John Wiley \& Sons; 2011. 